\title{
Effect of Silicone Coupling Agent on Dielectric Properties of Barium
}

Titanate/Silicone Elastomer Composites

\section{Chen Guo, Masayoshi Fuji*}

\section{fuji@nitech.ac.jp}

Advanced Ceramics Research Center, Nagoya Institute of Technology, Honmachi 3-101-1, Tajimi, Gifu 507-0033, Japan

Abstract: $\mathrm{BaTiO}_{3}$ is a type of ceramic with a high dielectric constant, while silicone is a type of elastomer with low elastic modules. Composites made by blending these two materials together can obtain both of their advantages, which has many possible applications in the area of actuators or mechanical sensors. In this study, to improve the dispersity of the $\mathrm{BaTiO}_{3}$ particles, a novel silicone coupling agent was used to modify the surface of the particles. TG and FTIR results showed that the coupling agent was successfully coated on the surface. Raw $\mathrm{BaTiO}_{3}$ and $\mathrm{BaTiO}_{3}$ modified by the silicone coupling agent were incorporated into the silicone elastomer to fabricate the $\mathrm{BaTiO}_{3} /$ silicone membranes. Particle size distribution measurements and SEM observations showed that the BT particles can obtain a higher compatibility with the silicone, and both the dispersity of the $\mathrm{BaTiO}_{3}$ particles and the dielectric properties of the $\mathrm{BaTiO}_{3} /$ silicone membranes were improved after the surface modification, even without a poling process during the fabrication or measurement. The measuring circuit containing the $\mathrm{BaTiO}_{3} /$ silicone membrane is expected to have several 
applications such as mechanical sensors.

Keywords: Barium Titanate; Silicone coupling agent; Silicone elastomer; Dielectric; Piezoelectric.

\section{Introduction}

$\mathrm{BaTiO}_{3}$ is a type of significant dielectric material with ferroelectric properties under its curie point, which is widely used in ceramic capacitors ${ }^{[1]}$. The dielectric constant of $\mathrm{BaTiO}_{3}$ significantly depends on the grain size; coarse-grained ceramics of 20 50 $\mathrm{nm} \mathrm{BaTiO}_{3}$ had a dielectric constant of about 1500 2000 at room temperature, while the room-temperature dielectric constant has a maximum of about 3500 4000 when the fine-grained $\mathrm{BaTiO}_{3}$ was about a $1 \mu \mathrm{m}$ size ${ }^{[2]}$. Although having such a high dielectric constant, $\mathrm{BaTiO}_{3}$ still suffers from some problems such as a low breakdown strength, brittleness and processing difficulties. On the other hands, despite of the low dielectric constant, polymeric materials have several advantages that are suitable for new types of electric applications such as low dielectric loss, high electric breakdown strength, low elastic modules and good processability ${ }^{[3,4]}$. Silicone is a type of polymeric material with an excellent flexibility and insulation; all types of silicones are known to be good dielectrics ${ }^{[5]}$. The silicone elastomer has always been considered as a type of inorganic polymer, comprised of a backbone of silicone-oxygen-silicone that is able to withstand a higher temperature than other elastomers ${ }^{[6,7]}$. Composites made by blending $\mathrm{BaTiO}_{3}$ and silicone together could 
obtain both a high dielectric constant and low elastic modules, which has many novel applications. For instance, a dielectric elastomer actuator can be made by sandwiching a membrane of dielectric composites between two compliant electrodes, and when loading a voltage difference between the compliant electrodes, compression in the thickness direction and stretching in the area direction of the elastomer membrane could occur due to the Coulombic force $e^{[8-13]}$.

Because of the relatively poor compatibility between inorganic dielectric particles and the organic silicone elastomer, agglomeration of the particles is difficult to avoid, leading to a higher dielectric loss and producing much pores that reduce the dielectric constant of the composites ${ }^{[4]}$. Obviously, it is of great significance to improve the compatibility between the inorganic dielectric particles and elastomers. Shu-Hui Xie, Bao-Ku Zhu and their coworkers ${ }^{[14]}$ synthesized polyimide/barium titanate composites by a colloidal process, finding that the $\mathrm{BaTiO}_{3}$ particles with the size of $100 \mathrm{~nm}$ were homogeneously dispersed in the polyimide matrix without aggregation. Dang Zhi-Min and his coworkers ${ }^{[15]}$ increased the dielectric constant in the PVDF matrix composites with $\mathrm{BaTiO}_{3}$ treated by the $1.0 \mathrm{wt} \%$ silane coupling agent, KH550. Their group also found that ${ }^{[16]}$ an appropriate silane coupling agent can be used to improve the interaction between the $\mathrm{BaTiO}_{3}$ and epoxy resin, producing high dielectric permittivity barium titanate/epoxy resin composites. L. Ramajo ${ }^{[17]}$ studied the influence of silane coupling agents on the microstructure and dielectric behavior of epoxy/BaTiO 3 composites, finding that their composites presented good dielectric properties and a strong dependence on the silane concentration. In this study, in order 
to improve the dispersity of the $\mathrm{BaTiO}_{3}$ particles and avoid agglomeration, a new type of silicone coupling agent was used to modify the surface of the particles by a novel super-critical method. Raw $\mathrm{BaTiO}_{3}$ particles and $\mathrm{BaTiO}_{3}$ particles modified by the silicone coupling agent were incorporated into the silicone elastomer to fabricate the $\mathrm{BaTiO}_{3} /$ silicone membranes. Although poling of the $\mathrm{BaTiO}_{3} /$ silicone membrane may enhance the dielectric property in a specific direction, it has not been carried out during the fabrication and measurement in order to simplify the experimental procedure. The dispersity of the $\mathrm{BaTiO}_{3}$ particles, dielectric properties and piezoelectric properties of the $\mathrm{BaTiO}_{3} /$ silicone membranes were evaluated.

\section{Experimental}

\subsection{Material}

$\mathrm{BaTiO}_{3}$ with particle sizes of 300nm and 500nm (with average crystallite sizes of 35.1nm and 31.4nm, respectively) were provided by the KCM Corporation, Japan; a two-component RTV silicone elastomer KE-103 (containing main component and crosslinker); silicone coupling agent, triethoxysilylethyl polydimethylsiloxyethyl dimethicone; silicone oil, KF-96-6CS (a type of low viscosity dimethylsiloxane silicone oil) were supplied by Shin-Etsu Chemical Co., Ltd., Japan; aqueous hydrogen peroxide (30\%) was provided by Tokyo Chemical Industry Co., Ltd., Japan; and ethanol, acetone and other reagents were obtained from Wako Pure Chemical Industries, Ltd., Japan.

2.2 Surface modifications of $\mathrm{BaTiO}_{3}$ using silicone coupling agent 
In this paper, $\mathrm{BT}$ is the abbreviation for $\mathrm{BaTiO}_{3}$, while $\mathrm{BT} 300$ and $\mathrm{BT500}$ are abbreviations of the $\mathrm{BaTiO}_{3}$ particles with sizes of 300nm and 500nm, respectively. Before modification, the surfaces of the BT particles were activated by introducing hydroxyl groups using aqueous hydrogen peroxide, according to the report of Shinn-Jen Chang ${ }^{[18]}$. Forty g of BT300 (or BT500) particles and 200mL of aqueous hydrogen peroxide (30\%) were added to a round bottom flask and the mixture was stirred at its boiling point $\left(106^{\circ} \mathrm{C}\right)$ for $5 \mathrm{~h}$ with refluxing, then the particles was washed several times by centrifugation using deionized water. The surface activated BT particles were then obtained after drying under vacuum at $60^{\circ} \mathrm{C}$ for $12 \mathrm{~h}$.

After the surface activation, the BT particles were modified by the silicone coupling agent at the super-critical state. Thirty-Five g of activated BT300 (BT500) particles, a predetermined amount of the silicone coupling agent, triethoxysilylethyl polydimethylsiloxyethyl dimethicone, and $80 \mathrm{~mL}$ hexane were added to a tubular bottle and mixed together. The coupling agent was added according to the amount listed in Table1. The mixture was then placed in an autoclave and heated to the supercritical state $\left(234.5^{\circ} \mathrm{C}, 3.01 \mathrm{MPa}\right)$, maintaining the condition for $1 \mathrm{~h}$. The coupling agent modified particles were obtained after cooling to room temperature, being washed several times by acetone and dried under vacuum at $60^{\circ} \mathrm{C}$ for $12 \mathrm{~h}$.

\subsection{Preparation of $\mathrm{BaTiO}_{3} /$ silicone composites}

The required quantity of the raw and modified BT300 or BT500 particles were mixed together with the main component of the silicone elastomer according to Table2 and Table3 using a high shearing blender that can load a high mechanical force. 
The crosslinker was next added to the mixture and totally dispersed, in which the ratio of $\mathrm{m}$ (main component): $\mathrm{m}$ (crosslinker) was controlled to 100:5. The BT/silicone membrane was finally obtained by pouring the mixture into a PTFE mold and allowing it to cure at room temperature for $72 \mathrm{~h}$.

\subsection{Characterization}

Trace chemical groups on the surface of the BT particles were detected by Fourier-transform infrared spectrometry (FTIR) using a JASCO FT/IR-6200 Fourier Transform infrared spectrometer. The thermogravimetric analysis (TG) was done at the heating rate of $10^{\circ} \mathrm{C} / \mathrm{min}$ in air using a Rigaku Thermo plus TG 8120. Scanning electron microscopy (SEM) images were obtained at the accelerating voltage of $15 \mathrm{kV}$ using a JEOL JSM-7600F field emission scanning electron microscope. The particle size distribution was measured by a MALVERN nanoseries particle size measuring instrument. The dielectric constant and dielectric loss ( $\tan \delta)$ were measured by a NF ZM 2371 LCR meter. The mechanical properties were measured by a SHIMADZU AGS-G Autograph. The instantaneous current was measured by a KEITHLEY 2000 multimeter.

\section{Results and discussion}

\subsection{Surface modifications of $\mathrm{BaTiO}_{3}$}

On the surface of the BT particles, the amount of active groups, such as amino groups or hydroxyl groups is too low to be modified. To solve this problem, hydroxyl groups were introduced on the surface using hydrogen peroxide to activate the surface 
of the BT particles according to the method of Shinn-Jen Chang ${ }^{[18]}$. When using boiling hydrogen peroxide to treat the $\mathrm{BT}$ particles, $\mathrm{H}_{2} \mathrm{O}_{2}$ will decompose and hydroperoxyl radicals $(\cdot \mathrm{OH})$ will generated on the surface. The $\cdot \mathrm{OH}$ will then react with $\mathrm{H}_{2} \mathrm{O}_{2}$ to form the hydroperoxyl radical $\left(\cdot \mathrm{O}_{2} \mathrm{H}\right)$ or further react with the produced $\cdot \mathrm{O}_{2} \mathrm{H}$ to form water and oxygen. Due to the highly acidic property of $\cdot \mathrm{O}_{2} \mathrm{H}$, hydroxyl groups can be easily produced by the reaction between $\cdot \mathrm{O}_{2} \mathrm{H}$ and the oxygen ions on the surface of the BT particles. In addition, the $\mathrm{O}_{2}^{-} \cdot$ radical can continue to react with water to produce hydroxyl anions in the water and reduce the $\mathrm{pH}$. The reaction procedures are shown in Figure 1 and the last equation shows the overall reaction.

Figure 1 shows the structure of the silicone coupling agent. It is a type of oligomer silicone that has a structure similar to the silicone elastomer and contains silicon-ethoxyl groups which can easily hydrolysis when in contact with moisture in the air. A predetermined ratio of BT particles and the silicone coupling agent were both dispersed into hexane and heated in an autoclave until reaching $234.5^{\circ} \mathrm{C}$ and 3.01MPa, at which the hexane will convert to the supercritical state. During this procedure, the $-\mathrm{OH}$ groups on the surface of the BT particles and $\mathrm{Si}-\mathrm{OH}$ groups from the silicone coupling agent can easily make contact and obtain a high reaction activity due to the excellent dissolving capacity of the supercritical hexane.

To estimate the amounts of coverage of the coupling agent on the BT surface, TG measurements of the raw BT particles and silicone coupling agent modified BT particles were carried out. The results are shown in Figure 2. It was measured in pure 
air and all samples were heated from room temperature to $600^{\circ} \mathrm{C}$. Up to this temperature, all of the coupling agent coated on the surfaces of particles should have absolutely reacted with $\mathrm{O}_{2}$. Organic side groups containing $-\mathrm{CH}_{3}$ and $-\mathrm{R}$ would be burned off and the $\mathrm{Si}-\mathrm{O}$ backbones will absorb $\mathrm{O}_{2}$ and remain as $\mathrm{SiO}_{2}$. At the same time, there was no weight variation in the BT particles. Therefore, the whole mass loss equals the weight lost due to the side groups of $-\mathrm{CH}_{3}$ and $-\mathrm{R}$ minus the obtained weight from the absorbed oxygen atoms. It can be seen from Figure 3 that: (1) when all the BT particles were heated to $600^{\circ} \mathrm{C}$, the weight losses of the raw or modified BT particles were determined by the modification ratio of the silicone coupling agent. For the BT300 particles, weight loss increases from almost 0 to $5.6 \%$ as the modification ratio by the increasing mass from 0 to 14.29\%. For the BT500 particles, the weight loss increases from almost 0 to $3.2 \%$ as the modification ratio by mass increasing from 0 to $14.29 \%$. The raw BT particles have only a tiny weight loss that could be caused by measuring error, while the silicone coupling agents modified BT particles have a greater weight loss. This result suggested that the silicone coupling agent has been successfully coated on the surface of the BT particles. (2) dramatic mass losses appeared when the BT-300-5 and BT-500-5 particles were heated to about $300^{\circ} \mathrm{C}$. It is considered that after the surface modification, a BT particle can get a 3-layer structure containing an inorganic BT particle core, chemical bonded coupling agent middle layer and physical attached coupling agent outer layer. At about $300^{\circ} \mathrm{C}$, the outer layer begins to burn and generates $\mathrm{SiO}_{2}$ as a fume that is difficult to deposit as a layer. The inner layer of the coupling agent is also beginning to burn, but the 
generated $\mathrm{SiO}_{2}$ easily deposits as a layer due to the Si-O-Metal chemical bond between the BT particles and silicone coupling agent. Thus it is sure that a modification ratio by mass of $14.29 \%$ is higher than the actual demand. BT-300-5 and BT-500-5 have thick physical attached coupling agent layers coated on their surfaces, leading to their apparent weight losses at about $300^{\circ} \mathrm{C}$; for the BT-300-3 and BT-500-3 particles, the modification ratio by mass of $8.57 \%$ is not more than the actual demand, so there is only a thin coupling agent layer physically attached to the surface and no dramatic weight loss can be observed at about $300^{\circ} \mathrm{C}$. (3) with the same coupling agent modification ratio, the weight loss of the modified BT-300 particles is higher than that of the modified BT-500 particles. This is because the BT-300 particles have the higher surface area of $3.81 \mathrm{~m}^{2} / \mathrm{g}$, compared to the surface area of $2.28 \mathrm{~m}^{2} / \mathrm{g}$ for the BT-500 particles. The theoretic thicknesses of the coated silicone coupling agent were roughly calculated according to the max weight losses of the samples in the TG measurement. To make the calculation simple, the reduced weight losses caused by the deposition of $\mathrm{SiO}_{2}$ were ignored. If the weight loss is $\mathrm{x}$ (\%), the average radius of the BT particles is $\mathrm{r}$, the density of the BT and silicone coupling agent are $\rho_{\mathrm{BT}}$ and $\rho_{\mathrm{s}}$, respectively, thickness $\mathrm{d}$ can be roughly calculated by

$$
\mathrm{d}=\frac{\mathrm{xr} \rho_{\mathrm{BT}}}{3(1-\mathrm{x}) \rho_{\mathrm{S}}}
$$

The results are listed in Table 4.

Figure 3 shows the FTIR spectra of the raw, $\mathrm{H}_{2} \mathrm{O}_{2}$ activated and silicone coupling agent modified BT particles. Hydroxyl groups grown on the surface of the BT particles after the $\mathrm{H}_{2} \mathrm{O}_{2}$ activation can be detected by the FTIR spectra. As shown in 
Figure 3, the absorption peak from about $525 \sim 550 \mathrm{~cm}^{-1}$ shows the vibration of the Ti-O bond in $\mathrm{BaTiO}_{3}{ }^{[19]}$. For both the BT-300 and BT-500 particles, the absorption bands at 3100 3700 $\mathrm{cm}^{-1}(-\mathrm{OH})$ become larger after activating the BT-300/BT-500 particles in boiling $\mathrm{H}_{2} \mathrm{O}_{2}$, which is strong evidence that a large number of hydroxyl groups have generated on the surface of the BT particles ${ }^{[20]}$. It can also be seen from the spectra that after the surface modification by the silicone coupling agents, many strong and narrow peaks appeared. Peaks at about $2950 \mathrm{~cm}^{-1}$ are evidence of the C-H bonds, peaks at about $1000 \mathrm{~cm}^{-1} \sim 1150 \mathrm{~cm}^{-1}$ are evidence of the Si-O bonds, and the peaks at about $1260 \sim 1320 \mathrm{~cm}^{-1}$ are evidence of the $\mathrm{CH}_{3}$-Si bonds ${ }^{[3,4,18,21]}$. These peaks clearly confirmed that the silicone coupling agent has been coated on the BT surface.

Figure 4 shows the results of the particle size distribution measurement. The dimethylsiloxane silicone oil, KF-96-6CS, was used because of its similar physical property to the silicone elastomer, KE-103, during the long-time uncured state in the fabricating procedure. BT300 and BT500 particles were added to the silicone oil and well dispersed by an ultrasonic homogenizer for $10 \mathrm{~min}$. The size distribution (particle diameter) of the BT particles was then measured by a MALVERN nano series particle size measuring instrument using the method of Non-contact Backward Light Scattering. The calculated Z-average sizes of the BT particles are listed in Table 5. The left side of Figure 4 shows the size distribution of the BT300 particles, while the right side shows the size distribution of the BT500 particles. It can be seen from Figure 4 that the sizes of the raw or modified BT300 particles ranged from about 400 950nm, while the sizes of the raw or modified BT500 particles ranged from 
about 450 1450nm. Compared to their average SEM particle sizes of 300nm and 500nm, the Non-contact Backward Light Scattering sizes have rather wider ranges, and the Z-average sizes of the BT300 and BT500 particles are several times greater than the values of the SEM particle sizes. It is considered that a BT particle in the silicone oil dispersion is mainly under the following forces: (a) force originated from Brownian motion of silicone molecules, (b) cohesive force between BT particles and (c) competition between gravity and flow resistance of BT particles in silicone oil. The origin of the cohesive force comes from the different chemical structures between the BT particles and silicone oil. According to the experience of "like dissolves like", the BT particles always have the trend of agglomerating together in the BT/silicone oil dispersion. These 3 kinds of forces are always competing together and tending to reach an equilibrium state. The force originating from the Brownian motion of silicone molecules tends to restrict the agglomeration of the BT particles and separate BT particles in the agglomerates from each other; the cohesive force between the BT particles tends to attract them together and maintain the shapes of the agglomerates; due to the low viscosity of the silicone oil and the very low polarity of the silicone molecules, gravity tends to make the BT particles precipitate vertically downward and agglomerate at the bottom. Due to the cohesive force, the BT particles are difficult to maintain a single state in the silicone oil dispersion, so several BT particles often agglomerate together and move as one single part, in addition, the amount of BT particles in one part of agglomerate is not fixed and always varying. This should be the reason why the sizes measured by the Non-contact Backward Light Scattering 
have such a wide range and totally larger than the SEM particle sizes. Without surface modification, the cohesive force between the BT particles will be maintained at a high level due to the strong surface polarity, so the agglomerates tend to become larger. Furthermore, a larger part of the agglomerate is much easier to be affected by gravity, which can cause serious sedimentation, thus reducing the distance between the BT particles. It can be seen from Table 5 that the Z-average sizes of the raw BT particles are larger than the silicone coupling agent surface modified BT particles. Especially, for the BT-500 particles, the gap of the Z-average size between the BT500-0 and BT500-1 particles is over 500nm. With the increasing modification ratio for the BT particles, the Z-average size becomes smaller, because the silicone coupling agent coated on the BT particles can not only considerably reduce the surface polarity of the particles, but also give them a surface chemistry similar to the silicone elastomer. This could apparently raise the compatibility between the BT particles and silicone substrate and effectively slow down the precipitating movement of the BT particles during the curing procedure, thus reducing their agglomeration in the silicone elastomer.

\subsection{Statistics of dispersity of BT/silicone composites based on SEM observations}

SEM images of the cross sections of the BT/silicone membranes and statistics for the dispersions of the BT particles in the silicone elastomer based on SEM observations are shown in Figures 5 and 6. BT/silicone membranes with a volume fraction of $20 \%$ were used. Cross sections of the samples were obtained by breaking 
them after soaking in liquid nitrogen. Back-scattered electron images were selected in order to observe the dispersing situations in the deeper areas of the composites. Several SEM photos were taken of the raw BT/silicone membrane (M300-0-20, M500-0-20) and BT/silicone membrane with BT modification ratios of $8.57 \%$ (M300-3-20, M500-3-20). For every kind of membrane, one of the SEM images is shown in the right parts of Figures 5 and 6, while the amount of the BT particles and amount of their agglomerates in the visual field were counted, respectively. In each kind of membrane, per 100 single particles, the amounts of the agglomerates with 1 5 particles, 6 10 particles, 11 15 particles, 16 20 particles and more than 20 particles are shown in the left parts of Figures 5 and 6. Part a in Figures 5 and 6 shows the situations of the raw BT/silicone membrane, while part b in Figures 5 and 6 shows the situations of the surface modified BT/silicone membrane.

In part a of Figures 5 and 6, large agglomerates of the BT300/BT500 particles and some voids can be clearly observed. The BT particles without surface modification are relatively hydrophilic, while the silicone elastomer is relatively hydrophobic, which could lead to the relatively weak compatibility and a large contact angle between them. Although fabricating of the samples was carried out in a vacuum, due to the high viscosity of the BT/silicone mixture and large contact angle between the BT particles and silicone monomer, it is almost impossible to eliminate all the bubbles or make the silicone monomer penetrate into all the gaps between of BT particles, which would cause agglomerates and voids in cured composites. At the same time, in Figures 5 and 6, statistics of dispersing situations from left pictures in part a show that 
many agglomerates consist of more than 5 particles are existing in the composites, agglomerates consist of less than 5 particles are insufficient, proving the low dispersity of raw BT/silicone composites.

In Part b of Figure 5 and 6, the BT particles seem to be dispersed much better than in part a. Even there are still agglomerates in the substrates, their sizes become much smaller. Particles were distributed to a wider range, many of them exist as single state. At the same time, in Figures 5 and 6, statistics of dispersing situations from left pictures in part b show that there are only a few agglomerates consist of more than 5 particles, the majority of the BT particles exist as the agglomerates consist of less than 5 particles. Observations of SEM images prove that surface modification using silicone coupling agent can obviously improve dispersity of the BT particles in the silicone elastomer.

\subsection{Dielectric properties of $\mathrm{BaTiO}_{3} /$ Silicone membranes}

Dielectric properties of the BT/silicone membranes were measured by LCR meter. Dielectric constants of BT/silicone composite membranes with different volume fractions at frequency from $400 \mathrm{~Hz}$ to $100 \mathrm{kHz}$ are shown in Figures 7 and 8 . It can be known that for every membrane with same volume fraction but different modification ratio, from low frequency to high frequency, there is no apparent variation observed from the dielectric constant-frequency curves, because the whole dielectric properties measurement were carried out at a low frequency area. Obviously, the dielectric constants are considerably improved as increasing of the volume fraction of BT 
particles. At frequency of $10 \mathrm{kHz}$, the dielectric constant of the pure silicone membrane is about 8, and it increased to about 35 for the raw BT-300/silicone membrane with the volume fracture of $40 \%$. It was also noted that the dielectric constant increased slightly after the surface modification by the silicone coupling agent. For example, at the frequency of $10 \mathrm{kHz}$, for the BT-300/silicone membrane with the volume fraction of $20 \%$, the dielectric constant changes from $15,18,18.5$ to 17.5 , as the modification mass ratio increased from $0,2.86 \%, 8.57 \%$ to $14.29 \%$, respectively. For the BT-300/silicone membrane with the volume fraction of $40 \%$, the dielectric constants are 34, 34, 35.5 to 35 for membranes with the modification mass ratios of $0,2.86 \%, 8.57 \%$ and $14.29 \%$, respectively. The BT-500/silicone membranes show a similar variation and have almost the same dielectric values with as the BT-300/silicone membranes.

The right side of Figures 7 and 8 show the dielectric losses of the BT/silicone membranes with different volume fractions at the frequencies from $400 \mathrm{~Hz}$ to $100 \mathrm{kHz}$. It was found that the dielectric losses of all the composite membranes have similar trends. For both the BT300/silicone and BT500/silicone composites, at a frequency below $1000 \mathrm{~Hz}$, the dielectric losses are very unstable and have relatively high values from about 0.03 to 0.06 ; when the frequency became higher, from about $1000 \mathrm{~Hz}$ to $50 \mathrm{kHz}$, the dielectric losses become stable and decreased to about 0 0.02; at a frequency higher than about $50 \mathrm{kHz}$, the dielectric losses slightly increased to about $0.01 \sim 0.03$. The origin of the dielectric loss by the composites may be due to the following factors ${ }^{[3]}$ : (1) direct current conduct (DC conduct); (2) space charge 
migration (interfacial polarization contribution), and (3) dipole loss caused by movement of the molecular dipoles. The reason for the variation in the dielectric loss is considered that, at a low frequency, electrons are easily to accumulated at the two sides of the electrodes, so the space charge can maintain a high level, making the direct current easier to occur, thus leading to a higher dielectric loss; if the frequency is improved to a rather high level near the vibration frequency of the dipoles, the dielectric loss caused by the dipole loss can become higher. This can explain why the dielectric loss in the middle frequency range has the lowest value and seems stable. It is also believed that the dielectric loss may decrease after the surface modification by the silicone coupling agent because if most of the BT particles are coated by coupling agent layers with an excellent insulation property, the conductivity through the BT particles could be significantly reduced, while accumulation and migration of the electric charge within the composites could also be restricted.

BT-500/silicone membranes show similar dielectric constants and dielectric losses as the BT-300/silicone membranes. For the surface modified BT-500/silicone membrane with the volume fraction of $40 \%$, the dielectric constant reached about 33 . The reason for the dielectric constant improvement after the surface modification of the BT particles by the silicone coupling agent will be described below.

As shown in Figure 9, the dispersion state of the BT particles in the silicone elastomer consists of 3 different arrangements. In the experiment, the BT particles were dispersed into the uncured silicone elastomer and always affected by gravity until curing. The silicone elastomer has a density of $0.93 \mathrm{~g} / \mathrm{cm}^{3}$ and the BT particles 
have a density of about $6.02 \mathrm{~g} / \mathrm{cm}^{3}$ that is greater than that of the silicone elastomer, thus in the curing procedure, the BT particles always tend to precipitate and agglomerate together. In Figure 9, part a shows the most serious situation, in which all the BT particles precipitated to the bottom and aggregated together, at last the whole membrane absolutely becomes to two parts: the silicone elastomer part in the upper side and the BT particles part in the bottom side. Part c shows the most well dispersed situation, in which all of the BT particles are well dispersed that every single particle is separated apart and uniformly distributed in the silicone substrates. Part a and part c show the extreme situations that could not actually exist. Part b is a kind of middle state between situations a and c. As an example, all of the BT particles are divided by a large amount of agglomerated units, and each unit contains several BT particles and every unit is relative uniformly distributed in the silicone substrates. The size of each unit is not constant and can vary as the amount of BT particles changes.

The dielectric constant of a vacuum is $\varepsilon_{0}$. The area of the membrane is $S$, the thickness of the membrane is d, and the volume fraction of the BT particles in the membrane is $\mathrm{x}$. Assume that for every membrane, there is a pair of parallel electrodes with areas of S sandwiching itself without a gap. The dielectric constant of the silicone elastomer, BT particles and the whole membrane is then $\varepsilon_{\mathrm{e}}$, $\varepsilon_{\mathrm{f}}$ and $\varepsilon$, respectively. The capacitance $\mathrm{C}$ of the whole membrane can be calculated as follows:

$$
\mathrm{C}=\frac{\varepsilon_{0} \varepsilon S}{\mathrm{~d}}
$$

For situation a in Figure 9, the capacitance of the silicone part and the BT part can be calculated, and capacitance of the whole membrane is reversely proportional to the 
capacitance of the silicone part and the BT part, so the capacitance of the whole membrane can be calculated as:

$$
C=\frac{1}{\frac{x}{C_{e}}+\frac{1-x}{C_{f}}}=\frac{C_{e} C_{f}}{x C_{f}+(1-x) C_{e}}=\frac{\frac{\varepsilon_{0}^{2} s^{2} \varepsilon_{e} \varepsilon_{f}}{d^{2}}}{\frac{\varepsilon_{0} S\left[x \varepsilon_{f}+(1-x) \varepsilon_{e}\right]}{d}}=\frac{\varepsilon_{0} S \varepsilon_{e} \varepsilon_{f}}{d\left[x \varepsilon_{e}+(1-x) \varepsilon_{f}\right]}
$$

Comparing (2) with (1), we can get the dielectric of the membrane as:

$$
\varepsilon=\frac{\varepsilon_{\mathrm{e}} \varepsilon_{\mathrm{f}}}{\mathrm{x} \varepsilon_{\mathrm{e}}+(1-\mathrm{x}) \varepsilon_{\mathrm{f}}}
$$

For situation c in Figure 9, the Lenchtenecker' logarithmic law ${ }^{[22]}$ can be used to calculate the dielectric constant of the membrane because of its good dispersity. The dielectric constant of the membrane can be calculated as:

$$
\log \varepsilon=(1-\mathrm{x}) \log \varepsilon_{\mathrm{e}}+\mathrm{x} \log \varepsilon_{\mathrm{f}}
$$

From (4), we can get the dielectric constant:

$$
\varepsilon=\varepsilon_{\mathrm{e}}^{(1-\mathrm{x})} \varepsilon_{\mathrm{f}}^{\mathrm{x}}
$$

BT particles of 300 500 $\mathrm{nm}$ has a dielectric constant of about $3600^{[23]}$. According to the previous result, the silicone elastomer has a dielectric constant of about 8. By substituting $\varepsilon_{\mathrm{e}}=8$ and $\varepsilon_{\mathrm{f}}=1600$ into (3) and (5), the theoretic dielectric constant of membrane in situation a and c in Figure 9 can be calculated. As shown in Table 6. It can be determined from the calculated results that during the wide volume fraction range from $10 \%$ to $50 \%$, the well dispersed $\mathrm{BT} /$ silicone membrane has a higher dielectric constant than the agglomerated one. BT/silicone membranes in reality should have a dielectric constant value between situation a and situation c in Figure 9. The dielectric constant of the composite membrane can be raised by improving the 
dispersity state of the BT particles, making it close to situation c in Figure 9.

\subsection{Piezoelectric properties of $\mathrm{BaTiO}_{3} /$ silicone composites}

As shown in Figure 10, the measuring circuit contained a pair of copper electrodes and a BT/silicone membrane sandwiched between the electrode pairs, acting as a simple parallel plate capacitor. A multimeter was mounted in the circuit to test the instantaneous current. A constant voltage of $5 \mathrm{~V}$ was loaded by a DC power, which is in the safety range and can be easily obtained. The membrane with electrodes was placed on a metal plate, and a periodic stress was loaded on the membrane by a metal cylinder. First, the cylinder was dropped at with a constant speed of $1000 \mathrm{~mm} / \mathrm{min}$, compressing the membrane until its thickness became half, then the cylinder rose up immediately with the same speed until returning to the original position. This procedure was periodically repeated. During the movement, the capacitance varies with the changing thickness, creating a charge-discharge recycle and a weak periodic current could be detected by the multimeter.

In the experiment, the BT300/silicone membrane (M300-3-40) with a thickness of 3.01mm and BT500/silicone membrane (M500-3-40) with a thickness of 2.21mm were used. Figure 11 shows the piezoelectric properties of the measuring circuit containing these membranes. The charge of the capacitor containing the BT/silicone membranes increased during the compression procedure and decreased during the stretching procedure. Variation in the charge was mainly considered because of the variation in the membrane thickness, which acts as the dielectric in the capacitor. Due 
to the small thickness of the membrane, the compressive elasticity quickly increased with the increasing compressive stress, making the variation in the thickness be nonlinear, that is, the charge quickly grows at first and soon loses its growing speed. It was found that the BT500/silicone membrane has a better performance.

Figure 12 shows that the periodic variation in the current occurs in the measuring circuit; about 3 cycles are shown. The varying period of the current and stress are about 250ms and 350ms for the measuring circuit containing the BT300/silicone membrane and BT500/silicone membrane, respectively. For example, for the circuit containing the BT300/silicone membrane, the stress increases from 0 to about $900 \mathrm{kPa}$ and returns to 0 with a sharp peak. It can be seen that from cycle 1 to cycle 3 , the max stress becomes much lower, which is due to the stress relaxation of the silicone elastomer. During the first half period, the immediately current increases from 0 to about 0.9nanoamperes, then soon decreases to 0 ; during the next half period, the current changes to the opposite direction. Like the first half period, it immediately increases from 0 to about 0.8 nanoamperes and soon decreases to 0 . The variation in the current does not show a linear trend mainly due to the nonlinear variation in the thickness. A similar variation in the current was shown in the measuring circuit with the BT500/silicone membrane, but the values of the max stress and max current are about twice times as high as those for BT300/silicone membrane. The better performance of the current/stress properties for the BT500/silicone membrane should be because of the smaller thickness of the BT500/silicone membrane and the differences in the dielectric constant and elastic modulus between the BT300/silicone 
membrane and BT500/silicone membrane. This kind of measuring circuit is expected to have some applications in mechanical sensors, benefiting by its rapid response of instantaneous electric signals, simple structures and low cost.

The theoretic calculations show similar results. The silicone elastomer has a Poisson' ratio of about $v=0.48^{[24]}$. For the BT/silicone membrane, if the strain in the thickness direction is $-\varepsilon$, the strain in the horizontal direction will become $v \varepsilon=0.48 \varepsilon$. The area for the cross section will be $(1+0.48 \varepsilon)^{2}$ times, volume will be $(1-\varepsilon)(1+0.48 \varepsilon)^{2}$ times of before, respectively. At the same time, the original thickness is d, and the original area is S. After loading a pressure on the membrane, its thickness will shrink to d' and area will stretch to S'. A pair of copper electrodes with the fixed diameter of $10 \mathrm{~mm}$ was used and loaded by the constant voltage of $\mathrm{U}=5 \mathrm{~V}$, and the effective area will be maintained as $S$ all the time. By fixing the speed of compression to $v=1000$ $\mathrm{mm} / \mathrm{min}$ and the time as t, as soon as the thickness becomes half, the speed is changed to the opposite direction and maintains $1000 \mathrm{~mm} / \mathrm{min}$. As shown in Figure 13, for the effective area sandwiched by the electrodes, the volume before pressing is $\mathrm{V}=\mathrm{Sd}$ and becomes V'=S'd' after pressing, while the effective volume becomes Sd'. Here $\mathrm{d}^{\prime}=(1-\varepsilon) \mathrm{d}, \quad \mathrm{S}^{\prime}=(1+v \varepsilon)^{2} \mathrm{~S}=(1+0.48 \varepsilon)^{2} \mathrm{~S}$, and $\mathrm{V}^{\prime}=(1-\varepsilon)(1+0.48 \varepsilon)^{2} \mathrm{~V}$. The BT particles dispersed in silicone are always moving during the deforming of the silicone substrates. The number of BT particles in the original effective area is $n$ and the average volume of one single particle is $\mathrm{V}_{0}$, thus the volume fraction in the original state will be $\mathrm{nV}_{0} / \mathrm{Sd}$. After the deformation, the number of BT particles in the effective area will be nS/S'. Movements of the BT particles caused by compression of 
the membrane are considered uniform, therefore, the volume fraction of the BT particles in the effective area can be calculated by $\frac{\mathrm{nV}_{0} \mathrm{~S} / \mathrm{S} \prime}{\mathrm{Sd} \prime}=\frac{\mathrm{nV}_{0}}{\mathrm{~S} \prime \mathrm{d} \prime}$. Thus, the volume fraction after deformation is $\mathrm{Sd} / \mathrm{S}^{\prime} \mathrm{d}^{\prime}=\mathrm{V} / \mathrm{V}^{\prime}=1 /\left[(1-\varepsilon)(1+0.48 \varepsilon)^{2}\right]$ times that of the volume fraction before deformation. Especially, when the membrane is pressed to half its thickness, the volume fraction will become about 1.3 times the original state. Variations of the dielectric constants for the BT/silicone membranes can be calculated according to the Lenchtenecker' logarithmic law. The dielectric constant will become about 77.4 after pressing the membrane to half its thickness.

For the measuring circuit, the capacity $\mathrm{C}$ can be calculated by the equation $\mathrm{C}=\frac{\varepsilon_{0} \varepsilon_{\mathrm{r}} \mathrm{S}}{\mathrm{d}-\mathrm{vt}}$ and the instantaneous current i can be calculated by

$$
\mathrm{i}=\frac{\mathrm{dQ}}{\mathrm{dt}}=\frac{\mathrm{d}(\mathrm{CU})}{\mathrm{dt}}=\mathrm{U} \frac{\mathrm{dC}}{\mathrm{dt}}=\varepsilon_{0} \mathrm{SU} \frac{\mathrm{d}\left(\frac{\varepsilon_{\mathrm{r}}}{\mathrm{d}-\mathrm{vt}}\right)}{\mathrm{dt}}=\left(\frac{\varepsilon_{0} S U}{\mathrm{~d}-\mathrm{vt}}\right) \frac{\mathrm{d} \varepsilon_{\mathrm{r}}}{\mathrm{dt}}+\frac{\varepsilon_{0} \varepsilon_{\mathrm{r}} \mathrm{vSU}}{(\mathrm{d}-\mathrm{vt})^{2}}
$$

during the compression stage; the capacity $\mathrm{C}$ can be calculated by the equation $\mathrm{C}=\frac{\varepsilon_{0} \varepsilon_{\mathrm{r}} \mathrm{S}}{0.5 \mathrm{~d}+\mathrm{vt}}$ and the instantaneous current $\mathrm{i}$ can be calculated by

$$
\mathrm{i}=\frac{\mathrm{dQ}}{\mathrm{dt}}=\frac{\mathrm{d}(\mathrm{CU})}{\mathrm{dt}}=\mathrm{U} \frac{\mathrm{dC}}{\mathrm{dt}}=\varepsilon_{0} \mathrm{SU} \frac{\mathrm{d}\left(\frac{\varepsilon_{\mathrm{r}}}{0.5 \mathrm{~d}+\mathrm{vt}}\right)}{\mathrm{dt}}=\left(\frac{\varepsilon_{0} \mathrm{SU}}{0.5 \mathrm{~d}+\mathrm{vt}}\right) \frac{\mathrm{d} \varepsilon_{\mathrm{r}}}{\mathrm{dt}}-\frac{\varepsilon_{0} \varepsilon_{\mathrm{r}} \mathrm{vSU}}{(0.5 \mathrm{~d}+\mathrm{vt})^{2}}
$$

during the returning stage. The theoretically calculated results of the average current have a range from 0 to 1.519nanoamperes for the BT300/silicone membrane and a range from 0 to 2.818nanoamperes for the BT500/Silicone membrane, which are similar to the experimental results. It is believed that the differences between the real values and theoretic values were caused by ignoring of the changing time of the pressing direction, the variation in Young's modulus, the effect of the BT particles on the Poisson's ratio of the silicone elastomer and the resistance of the measuring circuit. 


\section{Summary}

A novel silicone coupling agent was used to modify the surface of the BT particles. The TG and FTIR results show that the coupling agent was successfully coated on the surface of the BT particles. The BT/silicone membranes were fabricated using raw BT particles and BT particles modified by the silicone coupling agent. The particle size distribution measurement and SEM observations showed that the BT particles can obtain a higher compatibility with the silicone, and their dispersity in the silicone substrate was considerably improved after the surface modification. The dielectric properties were evaluated by an LCR meter, and the results show that the dielectric constants of the composite membranes increased after improving the dispersion states of the BT particles by the surface modification. Theoretic calculations from extreme cases proves that agglomeration of the BT fillers in the vertical direction could seriously reduce the dielectric constants of the composites membranes and the dielectric constant can be raised by improving the dispersion of the BT particles. Even without a poling process in the fabrication or measurement, the current generated by variation of the BT/silicone membrane was detected, which is expected to have applications in mechanical sensors due to its rapid response of instantaneous electric signals, simple structures and low costs.

\section{Acknowledgment}

The authors gratefully acknowledge support from the Advanced Low Carbon 
Technology Research and Development Program (ALCA) of the Japan Science and Technology Agency (JST). The authors also acknowledge the support from the KCM Corporation and Shin-Etsu Chemical Co., Ltd.

\section{References}

[1] D. Hennings, G. Rosenstein, Temperature-Stable Dielectrics Based on Chemically Inhomogeneous $\mathrm{BaTiO}_{3}$, J. Am. Ceram. Soc. 67 (1984) 249-254. doi:10.1111/j.1151-2916.1984.tb18841.x.

[2] G. Arlt, D. Hennings, G. De With, Dielectric properties of fine-grained barium titanate ceramics, J. Appl. Phys. 58 (1985) 1619-1625. doi:10.1063/1.336051.

[3] K. Yang, X. Huang, Y. Huang, Fluoro-polymer@ $\mathrm{BaTiO}_{3}$ Hybrid Nanoparticles prepared via RAFT polymerization: Toward Ferroelectric Polymer Nanocomposites with High Dielectric Constant and, Chem. 25 (2013) 2327-2338. http://pubs.acs.org/doi/abs/10.1021/cm4010486.

[4] L. Xie, X. Huang, Y. Huang, K. Yang, P. Jiang, Core@Double-Shell Structured $\mathrm{BaTiO}_{3}-$ Polymer Nanocomposites with High Dielectric Constant and Low Dielectric Loss for Energy Storage Application, J. Phys. Chem. C. 117 (2013) 2252522537. doi:10.1021/jp407340n.

[5] E. a. Cherney, Silicone rubber dielectrics modified by inorganic fillers for outdoor high voltage insulation applications, Annu. Rep. - Conf. Electr. Insul. Dielectr. Phenomena, CEIDP. 2005 (2005) 1-9. doi:10.1109/CEIDP.2005.1560607.

[6] S. Nayak, M. Rahaman, a. K. Pandey, D.K. Setua, T.K. Chaki, D. Khastgir, 
Development of poly(dimethylsiloxane)-titania nanocomposites with controlled dielectric properties: Effect of heat treatment of titania on electrical properties, J. Appl. Polym. Sci. 127 (2013) 784-796. doi:10.1002/app.37777.

[7] J.W. Liou, B.S. Chiou, Dielectric tunability of barium strontium titanate / silicone-rubber composite, Electron. Eng. 10 (1998) 2773-2786.

[8] Y. Liu, L. Liu, Z. Zhang, J. Leng, Dielectric elastomer film actuators: characterization, experiment and analysis, Smart Mater. Struct. 18 (2009) 095024. doi:10.1088/0964-1726/18/9/095024.

[9] F. Carpi, D.D. Rossi, Improvement of electromechanical actuating performances of a silicone dielectric elastomer by dispersion of titanium dioxide powder, Dielectr. Electr. Insul. IEEE Trans. $12 \quad$ (2005) 835-843. doi:10.1109/TDEI.2005.1511110.

[10] F. Carpi, G. Gallone, F. Galantini, D. De Rossi, Silicone-Poly (hexylthiophene) Blends as Elastomers with Enhanced Electromechanical Transduction Properties, Adv. Funct. Mater. 18 (2008) 235-241. doi:10.1002/adfm.200700757.

[11] B. Kussmaul, S. Risse, G. Kofod, R. Waché, M. Wegener, D.N. McCarthy, et al., Enhancement Of Dielectric Permittivity And Electromechanical Response In Silicone Elastomers: Molecular Grafting Of Organic Dipoles To The Macromolecular Network, Adv. Funct. Mater. 21 (2011) 4589-4594. doi:10.1002/adfm.201100884.

[12] A. O’Halloran, F. O’Malley, P. McHugh, A review on dielectric elastomer actuators, technology, applications, and challenges, J. Appl. Phys. 104 (2008) 1-10. 
doi:10.1063/1.2981642.

[13] P. Brochu, Q. Pei, Advances in Dielectric Elastomers for Actuators and Artificial Muscles, Macromol. Rapid Commun. $31 \quad$ (2010) 10-36. doi:10.1002/marc.200900425.

[14] Shu-Hui Xie, Bao-Ku Zhu, Xiu-Zhen Wei, Zhi-Kang Xu, You-Yi Xu, Polyimide/BaTiO 3 composites with controllable dielectric properties, Composites Part A: Applied Science and Manufacturing. 36 (2005) 1152-1157.

[15] Dang, Zhi-Min, Wang Hai-Yan, Xu Hai-Ping, Influence of silane coupling agent on morphology and dielectric property in $\mathrm{BaTiO}_{3}$, polyvinylidene fluoride composites. Applied Physics Letters. 89 (2006) 112902.

[16] Zhi-min Dang, Yan-Fei Yu, Hai-Ping Xu, Jinbo Bai, Study on microstructure and dielectric property of the $\mathrm{BaTiO}_{3} /$ epoxy resin composites, Composites Science and Technology. 68 (2008) 171-177.

[17] L. Ramajo, M.S. Castro, M.M. Reboredo, Effect of silane as coupling agent on the dielectric properties of $\mathrm{BaTiO}_{3}$-epoxy composites, Composites Part A: Applied Science and Manufacturing. 38 (2007) 1852-1859.

[18] S.-J. Chang, W.-S. Liao, C.-J. Ciou, J.-T. Lee, C.-C. Li, An efficient approach to derive hydroxyl groups on the surface of barium titanate nanoparticles to improve its chemical modification ability, J. Colloid Interface Sci. 329 (2009) 300-305. doi:10.1016/j.jcis.2008.10.011.

[19] X. Jin, D. Sun, M. Zhang, Y. Zhu, J. Qian, Investigation on FTIR spectra of barium calcium titanate ceramics, J. Electroceramics. 22 (2009) 285-290. 
doi:10.1007/s10832-007-9402-1.

[20] T. Kondo, The assignment of IR absorption bands due to free hydroxyl groups in cellulose, Cellulose. 4 (1997) 281-292. doi:10.1023/A:1018448109214.

[21] Y. Hasegawa, K. Okamura, Synthesis of continuous silicon carbide fibre Part 4 The structure of polycarbosilane as the precursor, J. Mater. Sci. 21 (1986) 321328. doi:10.1007/BF01144739.

[22] R. Sengupta, S. Chakraborty, S. Bandyopadhyay, S. Dasgupta, R. Mukhopadhyay, K. Auddy, et al., A Short Review on Rubber / Clay Nanocomposites With Emphasis on Mechanical Properties, Engineering. 47 (2007) 21-25. doi:10.1002/pen.

[23] S. Wada, H. Yasuno, T. Hoshina, S.-M. Nam, H. Kakemoto, T. Tsurumi, Preparation of nm-Sized Barium Titanate Fine Particles and Their Powder Dielectric Properties, Jpn. J. Appl. Phys. 42 (2003) 6188-6195. doi:10.1143/JJAP.42.6188.

[24] N. Bowden, S. Brittain, A. Evans, Spontaneous formation of ordered structures in thin films of metals supported on an elastomeric polymer, Nature. 393 (1998) 146149. doi:10.1038/30193. 


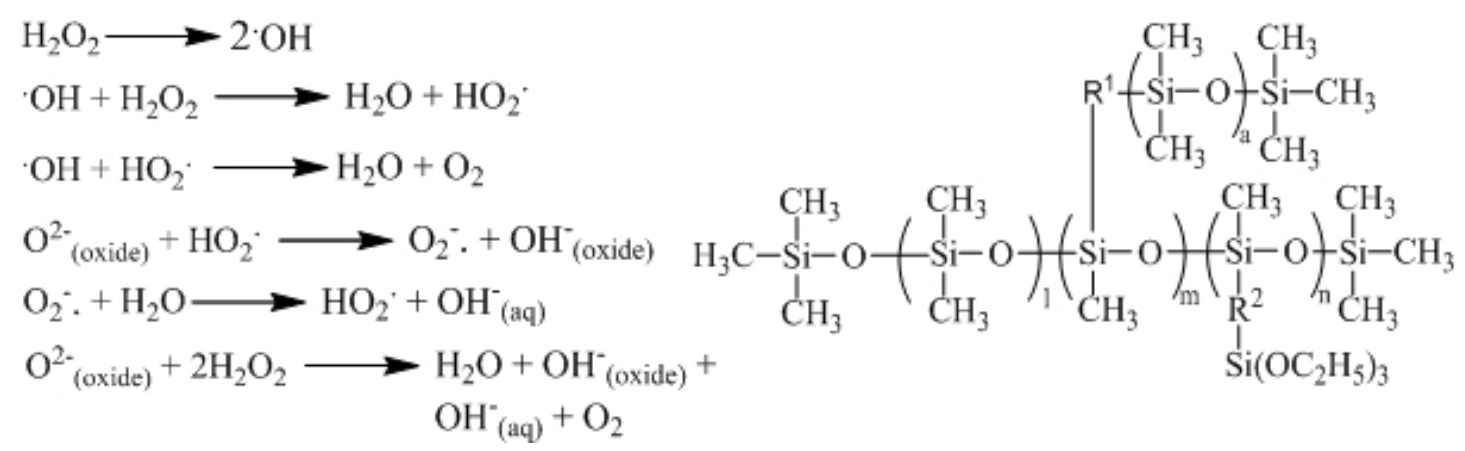

Fig. 1 Mechanism of coupling agent modification reaction and structure of silicone coupling agent 


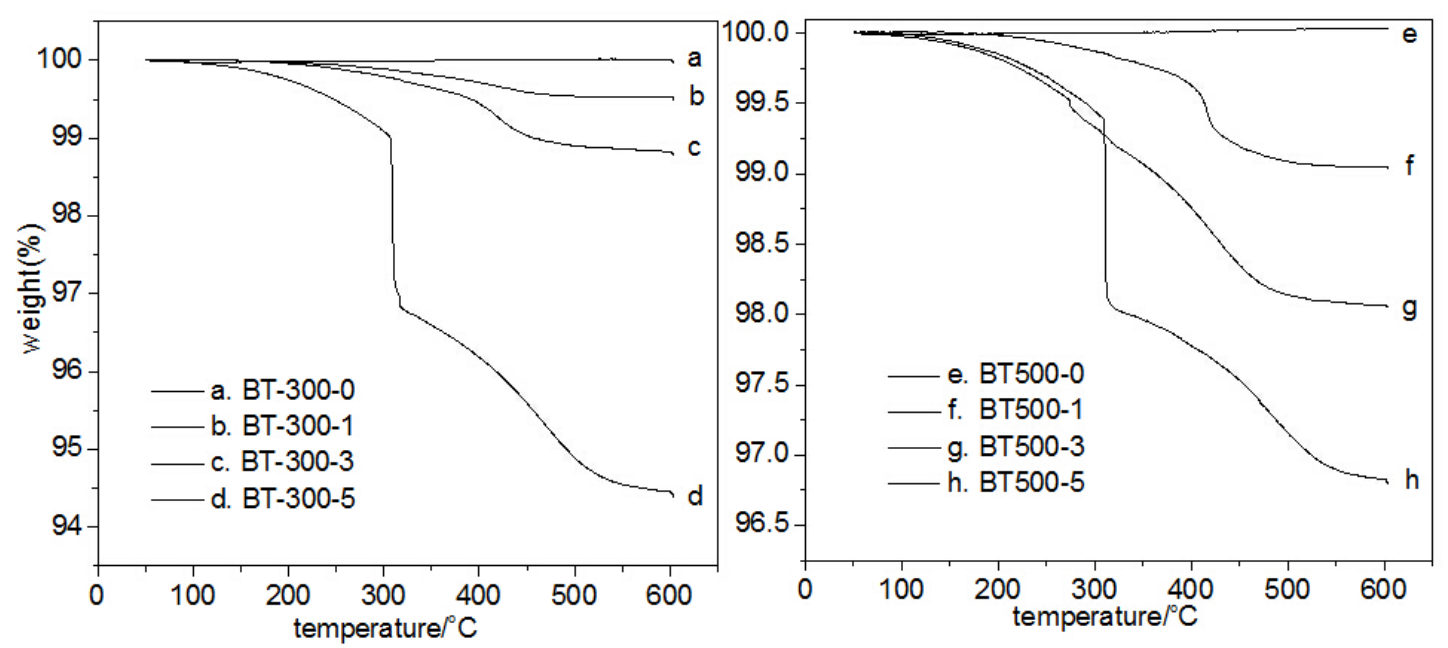

Fig. 2 TG results of raw and silicone coupling agent modified BT particles 


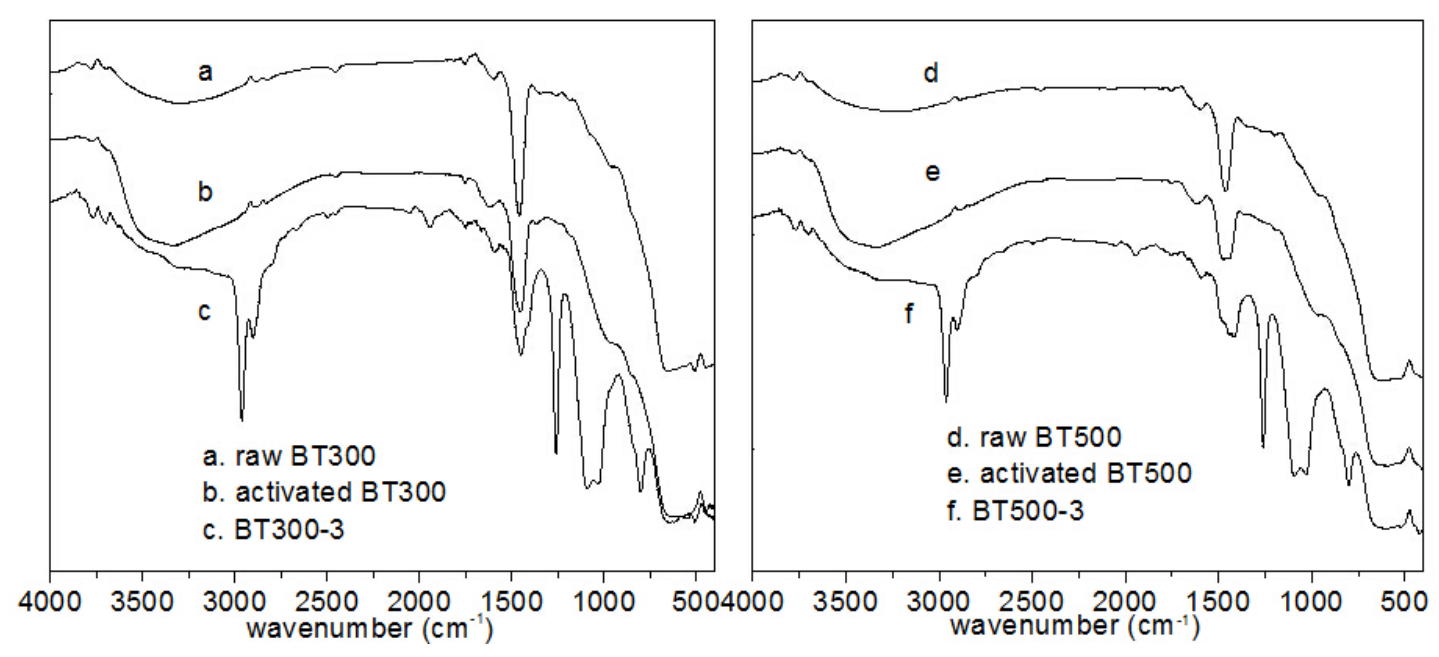

Fig. 3 FTIR spectra of raw and silicone coupling agent modified BT particles 


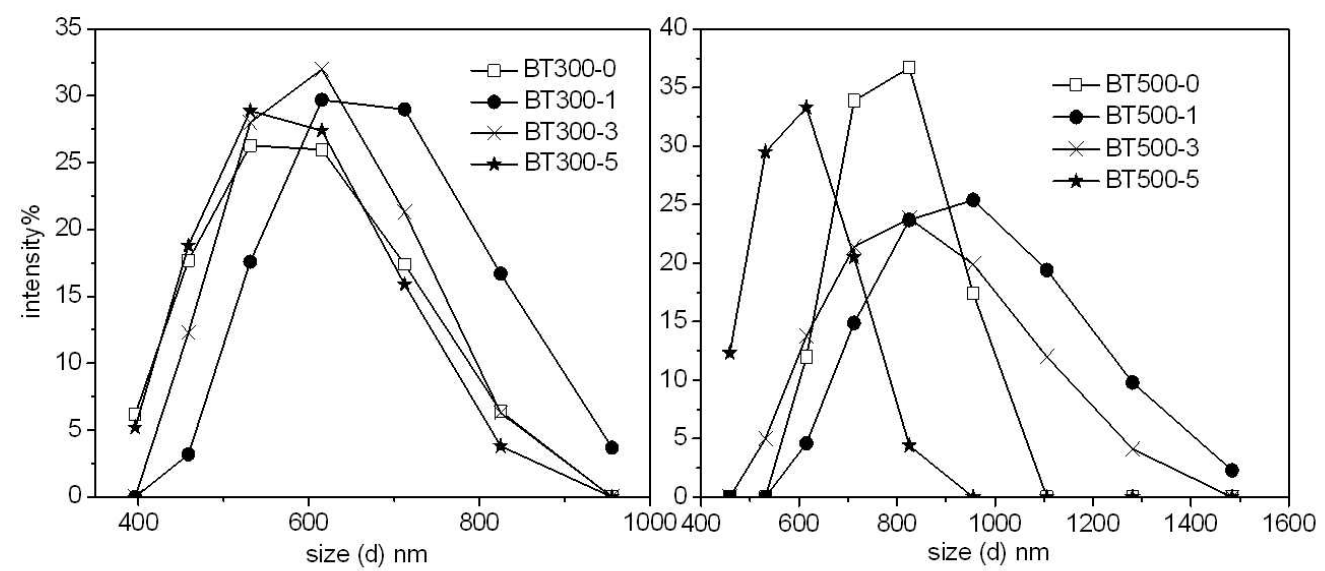

Fig. 4 Particle size distributions of raw and silicone coupling agent modified BT particles in silicone oil 

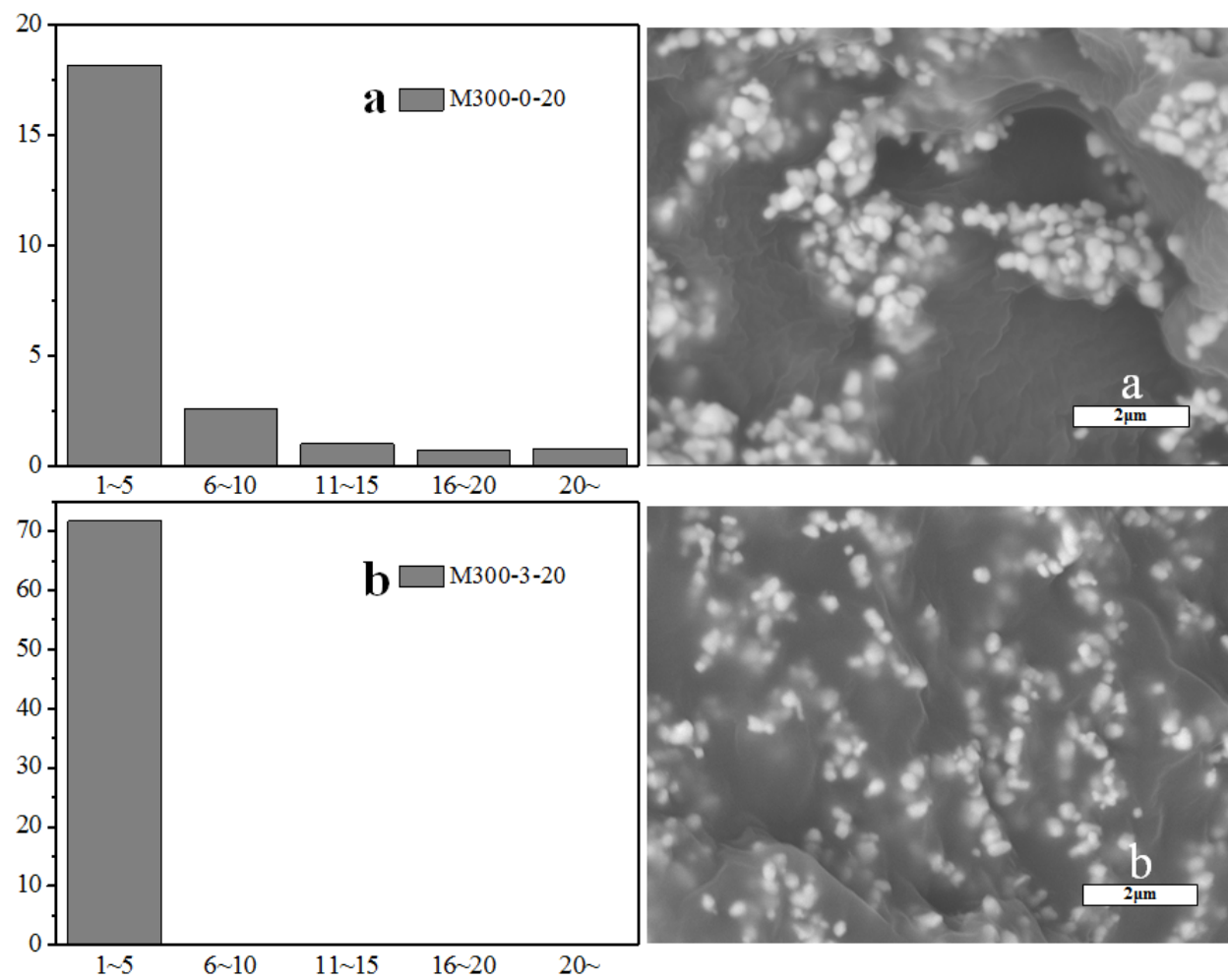

Fig. 5 Dispersity statistics and SEM images of cross section of BT300/silicone membranes a. M300-0-20 b. M300-3-20
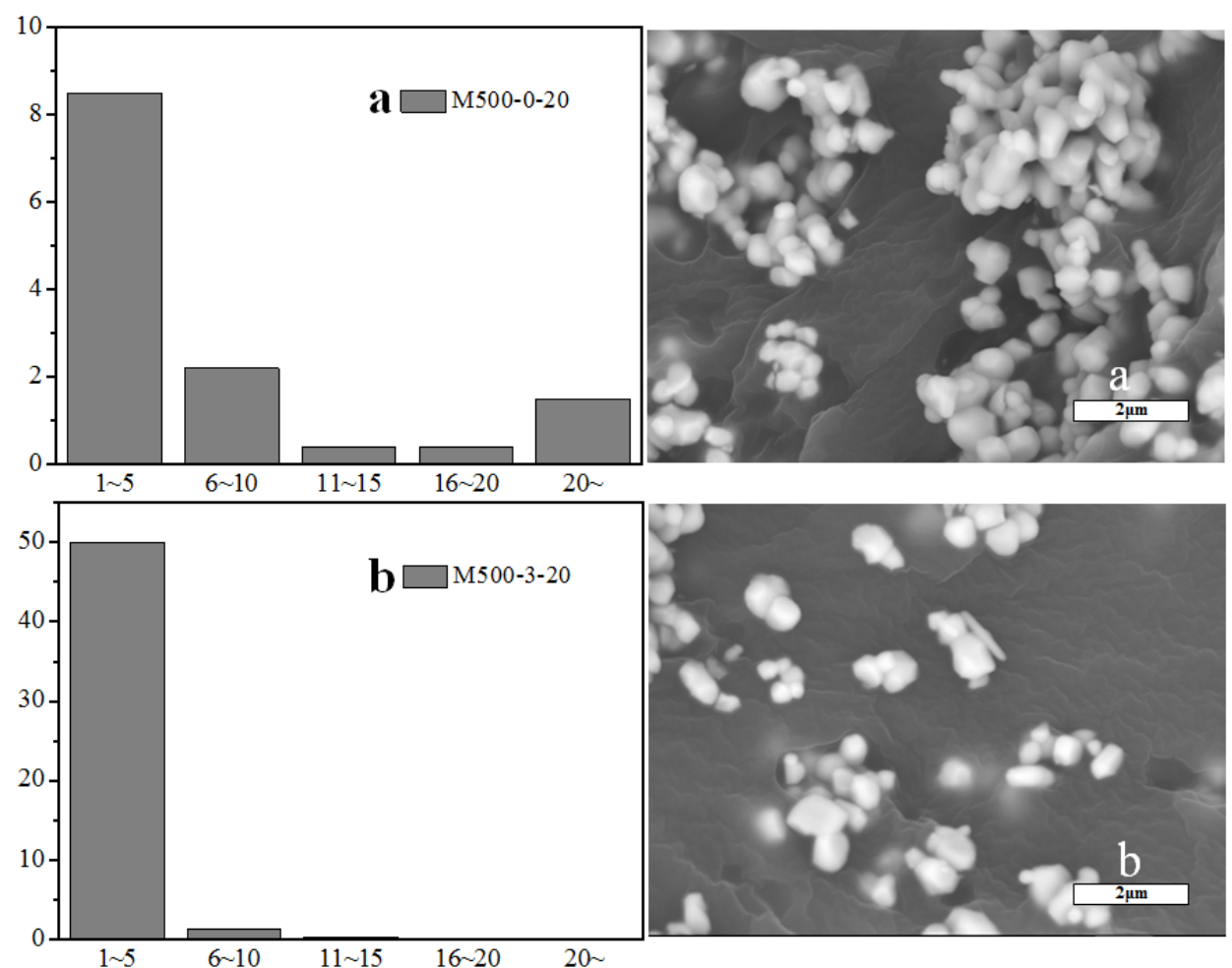

Fig. 6 Dispersity statistics and SEM images of cross section of BT500/silicone membranes a. M500-0-20 b. M500-3-20 

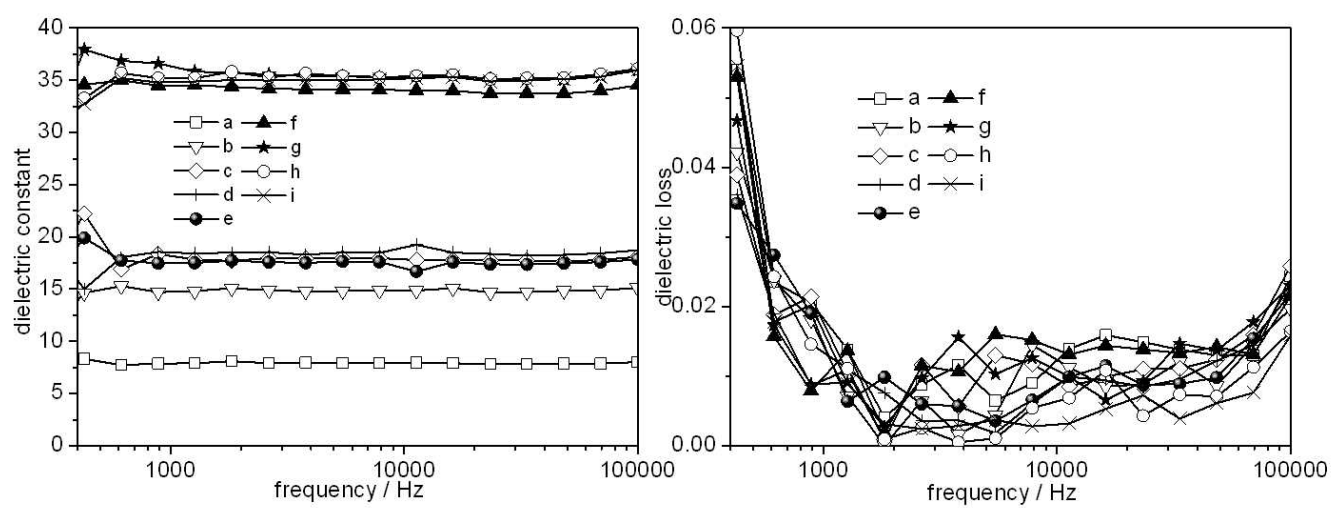

Fig. 7 Dielectric constants and dielectric losses $(\tan \delta)$ of BT300/silicone membranes at different frequencies

a. Pure silicone b. M300-0-20 c. M300-1-20 d. M300-3-20 e. M300-5-20

f. M300-0-40 g. M300-1-40 h. M300-3-40 i. M300-5-40 

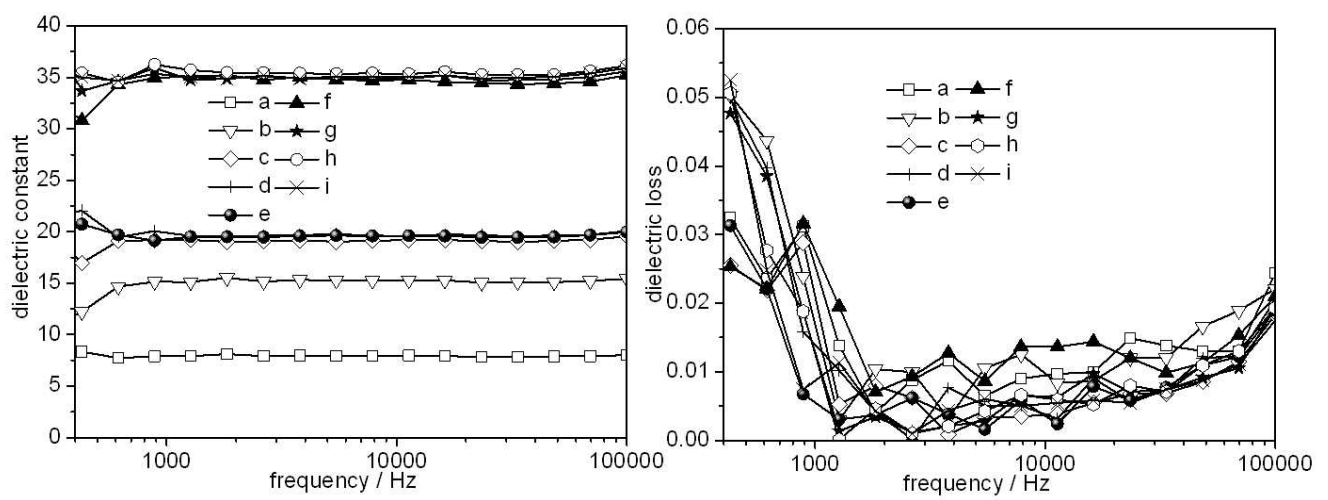

Fig. 8 Dielectric constants and dielectric losses $(\tan \delta)$ of BT500/silicone membranes at different frequencies

a. Pure silicone b. M500-0-20 c. M500-1-20 d. M500-3-20 e. M500-5-20

f. M500-0-40 g. M500-1-40 h. M500-3-40 i. M500-5-40 


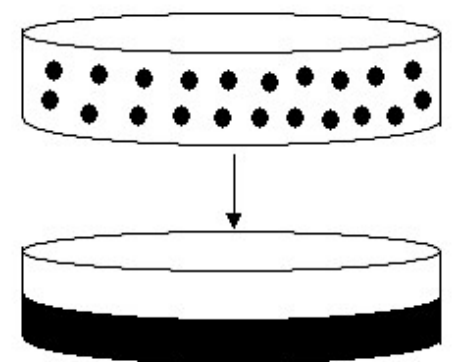

a
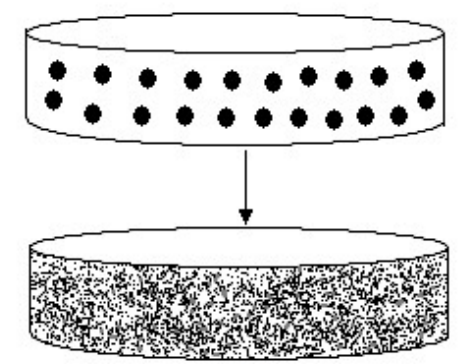

b

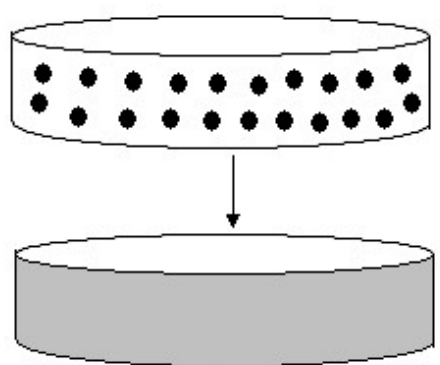

C

Fig. 9 Theoretical models of BT/silicone membranes

a: the most serious agglomeration that is absolutely divided by two parts

b: middle state between a and c

c: the most well-dispersed state that every single particle is separated apart and uniformly distributed 

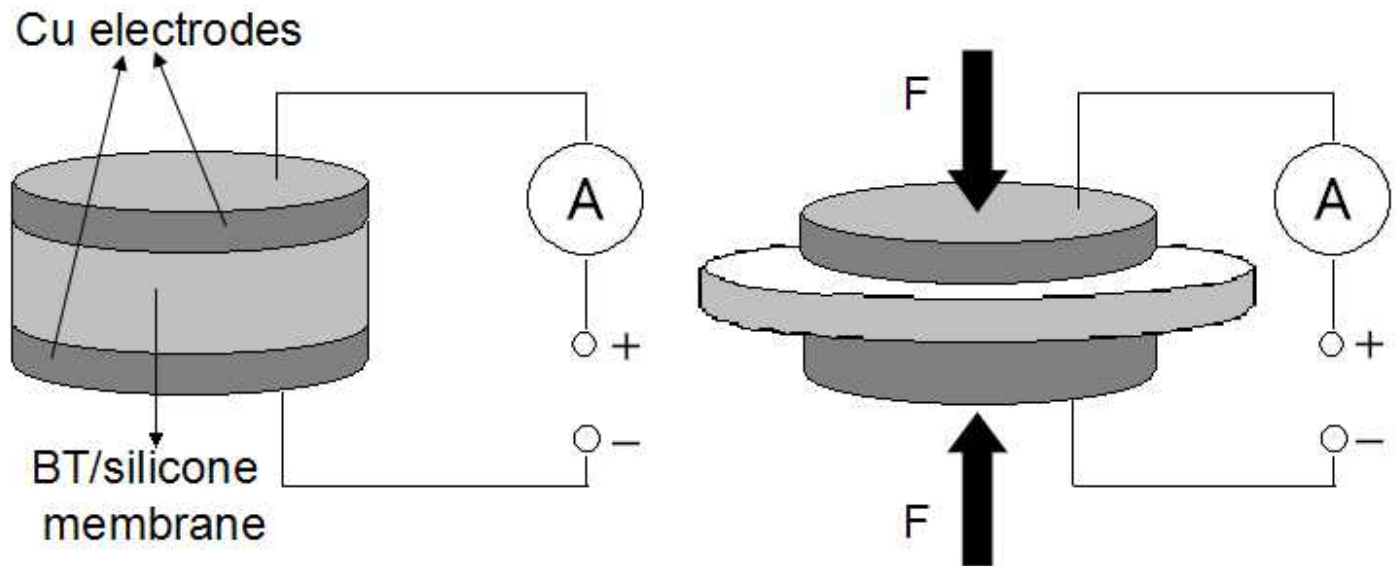

Fig. 10 Measuring circuit for BT/silicone membranes 


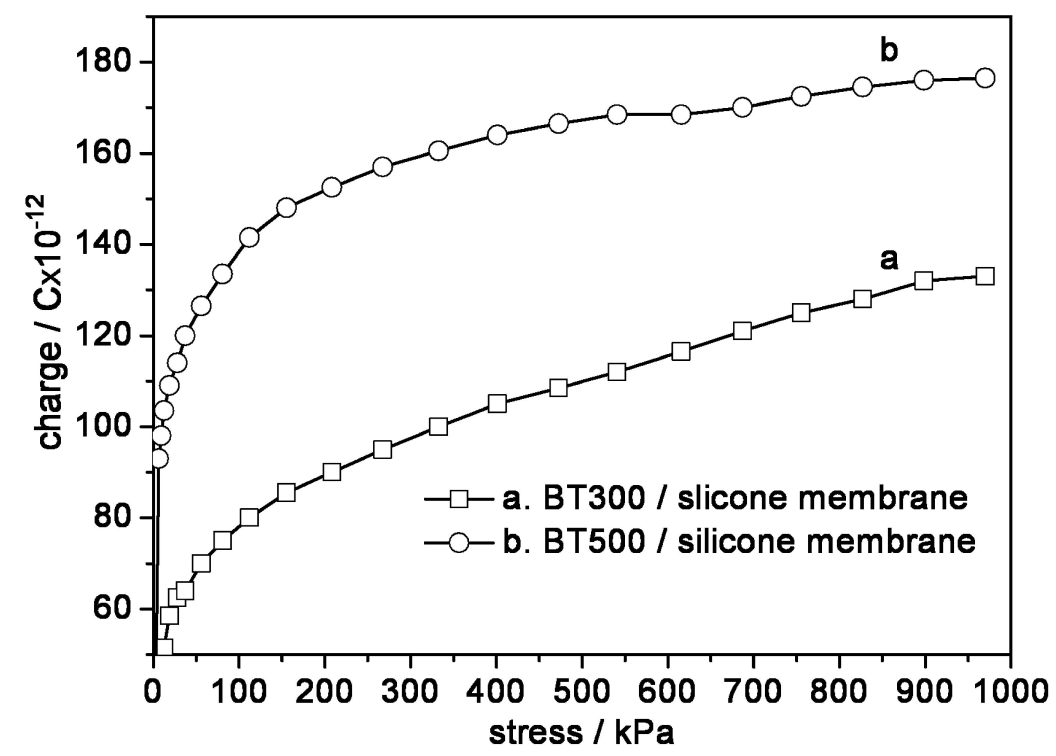

Fig. 11 Charge vs. stress curves of BT/silicone membranes 


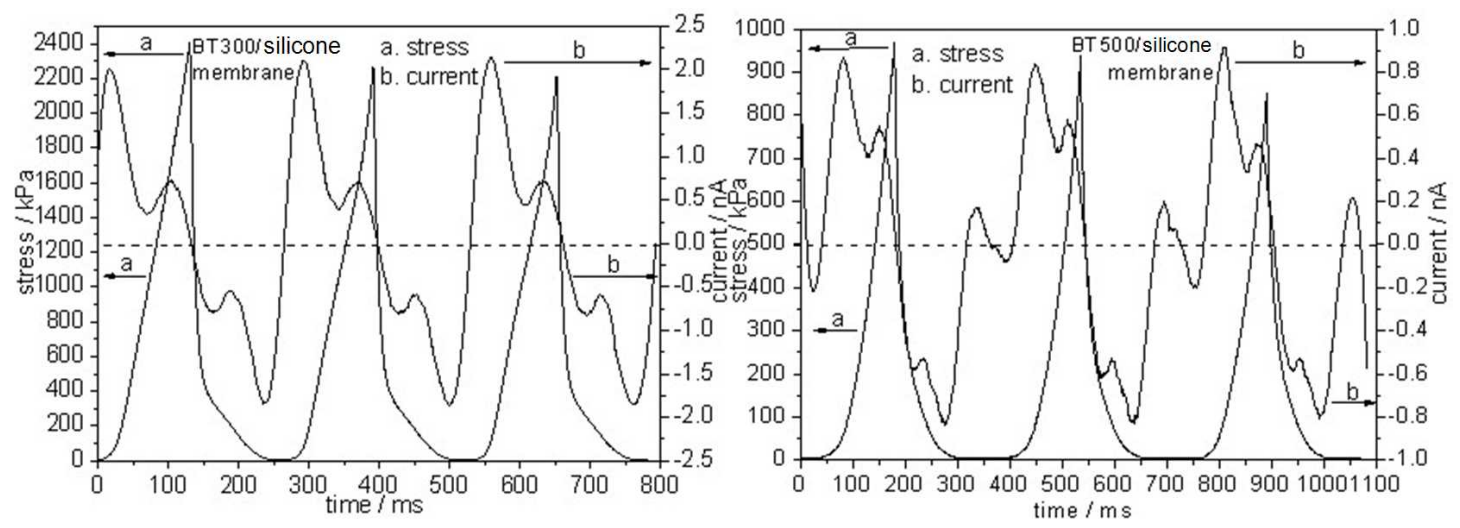

Fig. 12 Periodic variations of stress and current of measuring circuit containing BT/silicone membranes 


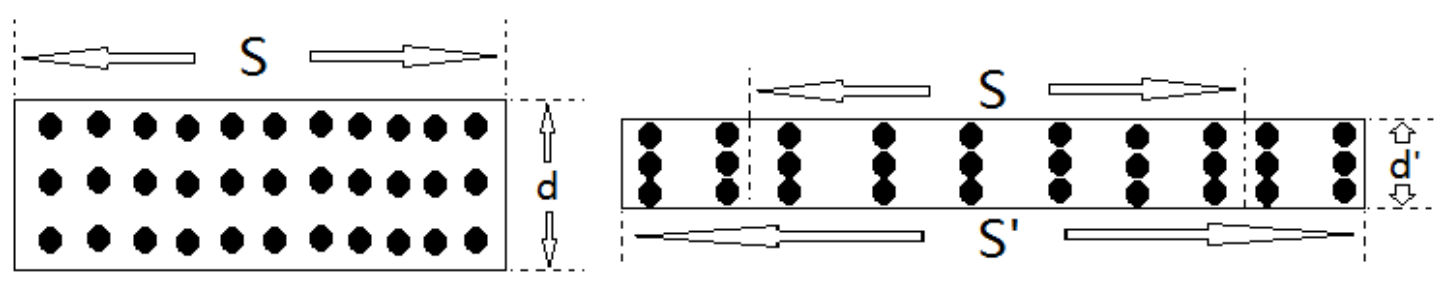

Fig. 13 Image of the thickness variation of BT/silicone membrane 
Table 1 Addition amounts of coupling agent

\begin{tabular}{lcccc}
\hline Modified BT300 (BT500) & $\begin{array}{c}\text { BT300-0 } \\
\text { (BT500-0) }\end{array}$ & $\begin{array}{c}\text { BT300-1 } \\
(B T 500-1)\end{array}$ & $\begin{array}{c}\text { BT300-3 } \\
(B T 500-3)\end{array}$ & $\begin{array}{c}\text { BT300-5 } \\
\text { (BT500-5) }\end{array}$ \\
\hline Activated BT300 (BT500) & $35 g$ & $35 g$ & $35 g$ & $35 g$ \\
Coupling agent & 0 & $1 \mathrm{~g}$ & $3 g$ & $5 \mathrm{~g}$ \\
m (coupling agent) / m (BT particles) & 0 & $2.86 \%$ & $8.57 \%$ & $14.29 \%$ \\
\hline
\end{tabular}


Table 2 Formula of BT300/silicone composites

\begin{tabular}{|c|c|c|c|c|c|c|c|c|c|}
\hline $\begin{array}{l}\text { BT300/ } \\
\text { silicone } \\
\text { membrane }\end{array}$ & $\begin{array}{l}\text { Membrane } \\
\text { of pure } \\
\text { silicone }\end{array}$ & $\begin{array}{l}\text { M300- } \\
0-20\end{array}$ & $\begin{array}{l}\text { M300- } \\
1-20\end{array}$ & $\begin{array}{l}\text { M300- } \\
3-20\end{array}$ & $\begin{array}{l}\text { M300- } \\
\text { 5-20 }\end{array}$ & $\begin{array}{l}\text { M300- } \\
0-40\end{array}$ & $\begin{array}{l}\text { M300- } \\
1-40\end{array}$ & $\begin{array}{l}\text { M300- } \\
3-40\end{array}$ & $\begin{array}{l}\text { M300- } \\
5-40\end{array}$ \\
\hline ВТ300-0 & & $6.02 \mathrm{~g}$ & & & & $12.04 \mathrm{~g}$ & & & \\
\hline ВТ300-1 & & & $6.02 \mathrm{~g}$ & & & & $12.04 \mathrm{~g}$ & & \\
\hline ВТ300-3 & & & & $6.02 \mathrm{~g}$ & & & & $12.04 \mathrm{~g}$ & \\
\hline ВТ300-5 & & & & & $6.02 \mathrm{~g}$ & & & & $12.04 \mathrm{~g}$ \\
\hline Silicone & $4.85 \mathrm{~g}$ & $3.88 \mathrm{~g}$ & $3.88 \mathrm{~g}$ & $3.88 \mathrm{~g}$ & $3.88 \mathrm{~g}$ & $2.91 \mathrm{~g}$ & $2.91 \mathrm{~g}$ & $2.91 \mathrm{~g}$ & $2.91 \mathrm{~g}$ \\
\hline $\begin{array}{l}\text { Volume } \\
\text { fraction }\end{array}$ & 0 & & & & & & & & \\
\hline
\end{tabular}


Table 3 Formula of BT500/silicone composites

\begin{tabular}{|c|c|c|c|c|c|c|c|c|c|}
\hline $\begin{array}{l}\text { BT500/ } \\
\text { silicone } \\
\text { membrane }\end{array}$ & $\begin{array}{l}\text { Membrane } \\
\text { of pure } \\
\text { silicone }\end{array}$ & $\begin{array}{l}\text { M500- } \\
0-20\end{array}$ & $\begin{array}{l}\text { M500- } \\
1-20\end{array}$ & $\begin{array}{l}\text { M500- } \\
3-20\end{array}$ & $\begin{array}{l}\text { M500- } \\
5-20\end{array}$ & $\begin{array}{l}\text { M500- } \\
0-40\end{array}$ & $\begin{array}{l}\text { M500- } \\
1-40\end{array}$ & $\begin{array}{l}\text { M500- } \\
3-40\end{array}$ & $\begin{array}{l}\text { M500- } \\
5-40\end{array}$ \\
\hline BT500-0 & & $6.02 \mathrm{~g}$ & & & & $12.04 \mathrm{~g}$ & & & \\
\hline BT500-1 & & & $6.02 \mathrm{~g}$ & & & & $12.04 \mathrm{~g}$ & & \\
\hline ВT500-3 & & & & $6.02 \mathrm{~g}$ & & & & $12.04 \mathrm{~g}$ & \\
\hline ВT500-5 & & & & & $6.02 \mathrm{~g}$ & & & & $12.04 \mathrm{~g}$ \\
\hline Silicone & $4.85 \mathrm{~g}$ & $3.88 \mathrm{~g}$ & $3.88 \mathrm{~g}$ & $3.88 \mathrm{~g}$ & $3.88 \mathrm{~g}$ & $2.91 \mathrm{~g}$ & $2.91 \mathrm{~g}$ & $2.91 \mathrm{~g}$ & $2.91 \mathrm{~g}$ \\
\hline $\begin{array}{l}\text { Volume } \\
\text { fraction }\end{array}$ & 0 & & & & & & & & \\
\hline
\end{tabular}


Table 4 Theoretic thickness of coated silicone coupling agent for BT particles

\begin{tabular}{cccc}
\hline Particles & Thickness $(\mathrm{nm})$ & Particles & Thickness $(\mathrm{nm})$ \\
\hline BT300-0 & 0 & BT500-0 & 0 \\
BT300-1 & 1.6 & BT500-1 & 5.3 \\
BT300-3 & 3.8 & BT500-3 & 10.1 \\
BT300-5 & 18.6 & BT500-5 & 17.3 \\
\hline
\end{tabular}


Table 5 Z-average sizes of BT particles

\begin{tabular}{cccc}
\hline Particles & Z-average size $(\mathrm{d}, \mathrm{nm})$ & Particles & Z-average size $(\mathrm{d}, \mathrm{nm})$ \\
\hline BT300-0 & 702.9 & BT500-0 & 1414.2 \\
BT300-1 & 637.1 & BT500-1 & 903.3 \\
BT300-3 & 588.6 & BT500-3 & 759.9 \\
BT300-5 & 570.1 & BT500-5 & 664.2 \\
\hline
\end{tabular}


Table 6 Theoretic dielectric constants of membrane in situation a and c

\begin{tabular}{cccccc}
\hline Volume fraction & $10 \%$ & $20 \%$ & $30 \%$ & $40 \%$ & $50 \%$ \\
\hline$\varepsilon$ in situation a & 8.9 & 10.0 & 11.4 & 13.3 & 16.0 \\
$\varepsilon$ in situation c & 14.7 & 27.1 & 50 & 92.1 & 169.7
\end{tabular}



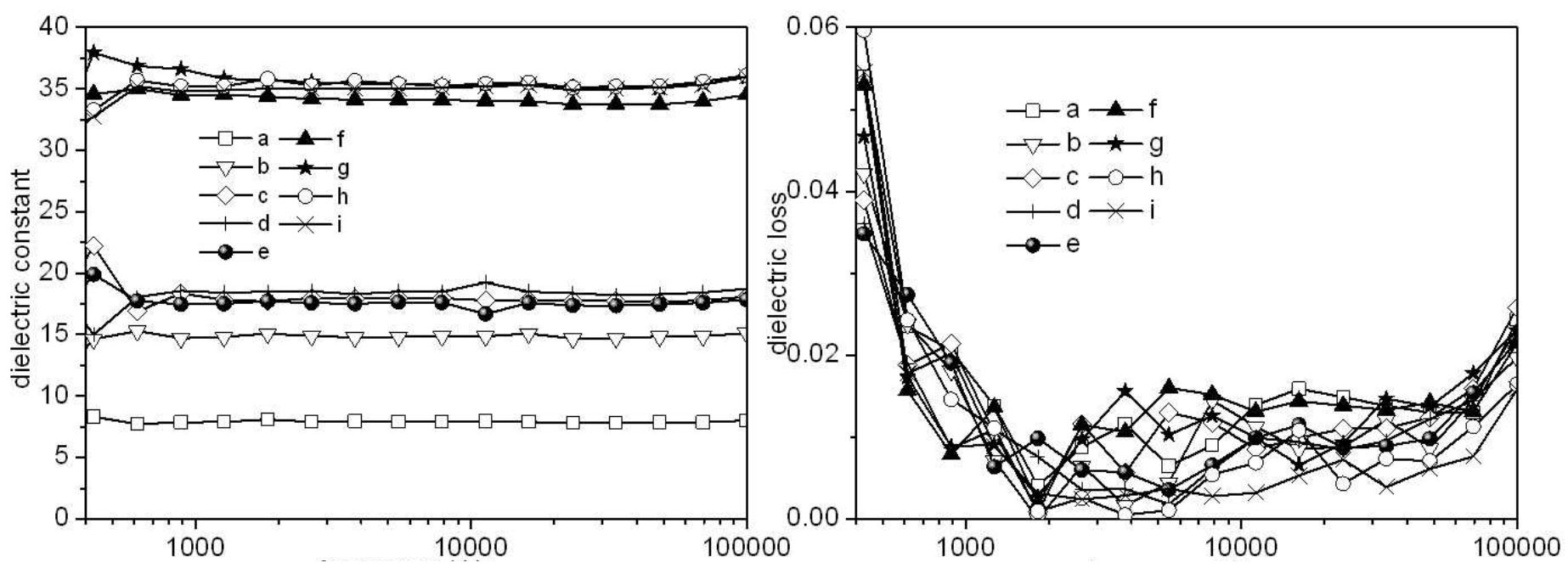

300nm $\mathrm{BaTiO}_{3} /$ silicone membrane
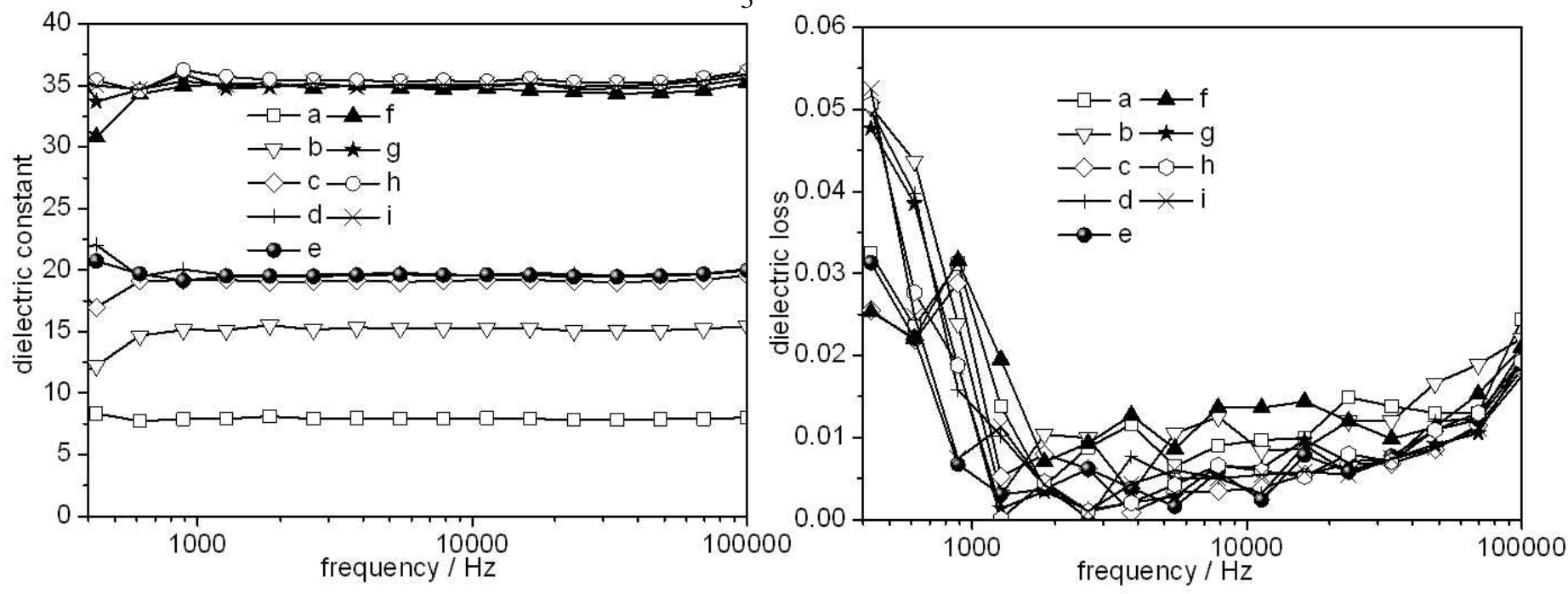

500nm $\mathrm{BaTiO}_{3} /$ silicone membrane

a. Pure silicone b. M300-0-20 c. M300-1-20 d. M300-3-20 e. M300-5-20

f. M300-0-40 g. M300-1-40 h. M300-3-40 i. M300-5-40

Dielectric constant and dielectric loss $(\tan \delta)$ of $\mathrm{BaTiO}_{3} /$ silicone membranes at different frequencies 